\title{
Skin Complete Response GvHD
}

National Cancer Institute

\section{Source}

National Cancer Institute. Skin Complete Response GvHD. NCI Thesaurus. Code

C126700.

An NIH skin score of 0 after previous GvHD involvement. 